\title{
Carcinoma Embrionário de Mediastino Posterior com Metástase Pulmonar: Relato de Caso
}

doi: https://doi.org/10.32635/2176-9745.RBC.2019v65n4.39

\author{
Posterior Mediastinum Embryonal Carcinoma with Pulmonary Metastasis: Case Report \\ Carcinoma Embrionario de Mediastino Posterior con Metástasis Pulmonar: Relato de Caso
}

Flávia Adrianne de Castro Grello'; Adrielly Elane Sousa Maia ${ }^{2}$; Katiane da Costa Cunha ${ }^{3}$

Resumo

Introduçáo: Os carcinomas embrionários são os mais raros e, geralmente, se apresentam quando já estáo associados com outros componentes de células germinativas. Possuem características clínicas e radiológicas similares aos tumores de saco vitelino. Relato do caso: Paciente G.A.S.L, sexo masculino, 30 anos, ex-tabagista e etilista. Iniciou com quadro de dores no hemitórax esquerdo em fevereiro de 2018 com extensão dos sintomas para a região da coluna torácica e lombar. Realizou tomografia de abdômen total e tórax, com resultado sugestivo de tumor de mediastino, nódulos pulmonares, material tecidual com densidade de partes moles no mediastino posterior e numerosas linfonodomegalias retroperitoneais, evoluiu com paraplegia de membros inferiores por compressão nervosa e com hipoestesia. Realizou biópsia de tumor de mediastino posterior à esquerda com resultado de neoplasia maligna epitelial e diagnóstico de carcinoma embrionário extragonodal pouco diferenciado. O paciente apresentou metástase pulmonar, confirmando que esses tumores frequentemente se infiltram nos órgãos adjacentes. A quimioterapia baseada em cisplatina é o tratamento padrão, levando à melhora da sobrevida em pacientes com esse tipo de tumor. Após a quimioterapia, houve diminuição do volume tumoral, porém, seguiu com a paraplegia de membros inferiores em razão da compressão nervosa. Conclusáo: Este estudo relata o caso de um paciente jovem, com tumor raro de células germinativas e metástase pulmonar, que evoluiu clinicamente estável após tratamento específico com quimioterápicos. Por ainda haver uma escassa literatura acerca do tema, este estudo traz novas evidências e achados.

Palavras-chave: Neoplasias do Mediastino; Metástase Neoplásica; Carcinoma Embrionário; Relatos de Casos.

\section{Abstract}

Introduction: Embryonal carcinomas are the rarest, and usually present when they are already associated with other components of germ cells. They have clinical and radiological features similar to yolk sac tumors. Case report: Patient G.A.S.L, male, 30 years old, former smoker and alcoholic. Initially, the patient reported pain in the left hemithorax in February 2018 with extension of the symptoms to the region of the thoracic and lumbar spine. A tomography of the total abdomen and chest was performed, with result suggestive of mediastinal tumor, pulmonary nodules, tissue material with soft tissue density in the posterior mediastinum and numerous retroperitoneal lymph node enlargement, which evolved with paraplegia of the lower limbs by nerve compression and hypoesthesia. It was conducted a biopsy of a mediastinal tumor posterior to the left with result of malignant epithelial neoplasia and diagnosis of extragonadal embryonic carcinoma very little differentiated. The patient presented pulmonary metastasis confirming that these tumors frequently infiltrate into the adjacent organs. Cisplatinbased chemotherapy is the standard treatment, leading to improved survival in patients with this type of tumor. After chemotherapy, the tumor volume decreased, but the patient continued with paraplegia of lower limbs due to nerve compression. Conclusion: This study reports the case of a young patient with a rare germ cell tumor and pulmonary metastasis who evolved clinically stable after specific chemotherapy treatment. Because there is still scarce literature on the subject, this study brings new evidences and findings. Key words: Mediastinal Neoplasms; Neoplasm Metastasis; Carcinoma, Embryonal; Case Reports.

\section{Resumen}

Introducción: Los carcinomas embrionarios son los más raros y generalmente se presentan cuando ya están asociados con otros componentes de células germinativas. Se presentan características clínicas y radiológicas similares a los tumores de saco vitelino. Relato del caso: Paciente G.A.S.L, sexo masculino, 30 años, ex tabaquista y etilista. Se inició con cuadro de dolores en el hemitórax izquierdo en febrero de 2018 con extensión de los síntomas para la región de la columna torácica y lumbar. Se realizó una tomografía de abdomen total y tórax, con resultado sugestivo de tumor de mediastino, nódulos pulmonares, material tisular con densidad de partes blandas en el mediastino posterior y numerosas linfonodomegalias retroperitoneales, evolucionó con paraplejia de miembros inferiores por compresión nerviosa y con hipoestesia. Se realizó biopsia de tumor de mediastino posterior a la izquierda con resultado de neoplasia maligna epitelial y diagnóstico de carcinoma embrionario extra gonodal poco diferenciado. El paciente presentó metástasis pulmonar confirmando que estos tumores frecuentemente se infiltran en los órganos adyacentes. La quimioterapia basada en cisplatino es el tratamiento estándar, llevando a la mejora de la supervivencia en pacientes con este tipo de tumor. Después de la quimioterapia hubo la disminución del volumen tumoral, sin embargo, siguió con la paraplejia de miembros inferiores debido a la compresión nerviosa. Conclusión: Este estudio informa el caso de un paciente joven con un tumor raro de células germinales y metástasis pulmonar que evolucionó clínicamente estable después de un tratamiento de quimioterapia específico. Debido a que todavía hay poca literatura sobre el tema, este estudio aporta nuevas pruebas y hallazgos.

Palabras clave: Neoplasias del Mediastino; Metástasis de la Neoplasia; Carcinoma Embrionario; Informes de Casos.

\footnotetext{
${ }^{1}$ Hospital Ophir Loyola. Pará (PA), Brasil. Orcid iD: https://orcid.org/0000-0003-3031-6682

${ }^{2}$ Hospital Ophir Loyola. Pará (PA), Brasil. Orcid iD: https://orcid.org/0000-0002-6940-2417

${ }^{3}$ Hospital Ophir Loyola. Pará (PA), Brasil. Orcid iD: https://orcid.org/0000-0001-5361-5090

Endereço para correspondência: Flávia Adrianne de Castro Grello. Travessa Angustura, 1961, Ed. Tereza Borsoi, Apto. 1403 - Pedreira. Pará (PA), Brasil. CEP 66080-180. E-mail: flaviaadrianne@hotmail.com
} 


\section{INTRODUÇÃO}

Os tumores de células germinativas mediastinais são neoplasias relativamente raras, responsáveis por apenas $1 \%$ a $4 \%$ de todos os tumores mediastinais, e menos de $1 \%$ de todos os tumores do mediastino é maligno de células germinativas ${ }^{1-3}$.

Pacientes com tumores de células germinativas mediastinais têm pior prognóstico quando comparados àqueles com origem de células primárias gonadais, especialmente no caso de tumores malignos de células germinativas não seminomatosos. A histogênese das tumores de células germinativas mediastinais não está completamente definida, mas acredita-se que os tumores provenham de células germinativas primordiais que não conseguem finalizar a migração normal ao longo da crista urogenital para as cristas gonadais no decorrer da embriogênese, ou distribuíram-se fisiologicamente para o fígado, medula espinhal e cérebro, a fim de desempenhar funçôes regulares ${ }^{3}$.

Os tumores de células germinativas mediastinais são classificados como seminomatosos ou não seminomatosos. Os não seminomatosos são histologicamente classificados como carcinoma embrionário, coriocarcinoma, tumor do saco vitelino, teratoma ou tumores combinados de células germinativas. Esses tumores geralmente são encontrados no mediastino e, na maioria dos casos, sáo pacientes do sexo masculino (15 a 35 anos $)^{4,5}$. Os carcinomas embrionários são os mais raros, e, geralmente, se apresentam quando já estão associados com outros componentes de células germinativas ${ }^{5,6}$.

$\mathrm{Na}$ maioria dos casos, os tumores malignos de células germinativas se desenvolvem de forma mais localizada com seu crescimento, comprimindo o tecido normal adjacente a ele. Normalmente, a disseminação linfática acontece antes da disseminação por via hematogênica. A primeira via de acometimento são os linfonodos retroperitoneais, logo após os para-aórticos, seguindo para os mediastinais e supraclaviculares. Já a disseminação hematogênica acontece de maneira mais tardia, ocorrendo de forma preferencial para pulmóes, fígado, cérebro e ossos também podem ser acometidos ${ }^{7}$.

Os tumores de células germinativas não seminomatosos possuem como característica o desenvolvimento de metástases de forma mais precoce, além de disseminar mais rapidamente pela via hematogênica. Além de possuir uma maior tendência à metástase, esse tipo de tumor ocasiona um pior prognóstico quando comparado aos do tipo seminomatoso em mesmo estágio 7 .

Este estudo possui como objetivo relatar o caso de um paciente portador de tumor de mediastino posterior, evoluindo com metástase pulmonar. A consulta bibliográfica foi feita como forma de se obter uma maior discussão e aprofundamento sobre o tema.

O trabalho proposto é um estudo de caso de indivíduo único, no qual a seleção do paciente foi realizada de acordo com achados clínicos e radiológicos encontrados por meio da busca direta ao prontuário, realizada no Hospital Ophir Loyola (HOL). A pesquisa iniciou-se mediante aprovação pelo Comitê de Ética em Pesquisa (CEP) da instituição (CAAE: 96279018.6.0000.5550) e isenção do Termo de Consentimento Livre e Esclarecido (TCLE).

\section{RELATO DO CASO}

Paciente G.A.S.L, sexo masculino, 30 anos, ex-tabagista e etilista. Em fevereiro de 2018, apresentou quadro de dores no hemitórax esquerdo, procurou atendimento médico com a realização de uma ultrassonografia com resultado de esteatose grau I (leve, com pequeno acúmulo de gordura), sendo prescritos apenas analgésicos.

Em razão da extensão dos sintomas para a região da coluna torácica e lombar posterior, houve a necessidade de o paciente ser internado em sua cidade natal. Durante a internação, realizou tomografia de abdômen total e tórax com contraste, com resultado sugestivo de tumor de mediastino com achados de hérnia discal L4-L5 e L5-S1, nódulos pulmonares de distribuição randômica, material tecidual com densidade de partes moles no mediastino posterior em situação vertebral à esquerda e discretamente à direita, e numerosas linfonodomegalias retroperitoneais (Figura 1).

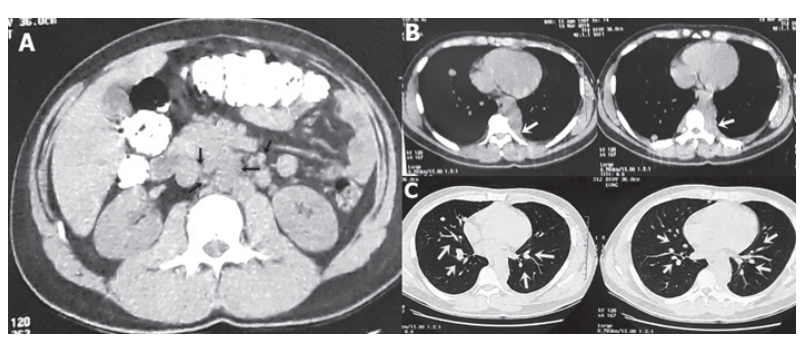

Figura 1. Tomografia computadorizada com contraste. A: linfonodomegalias representadas pelas setas pretas; B: setas brancas representando a massa tecidual de partes moles no mediastino posterior; C: setas brancas representando os nódulos pulmonares

O paciente foi encaminhado para o $\mathrm{HOL}$, em março de 2018, onde evoluiu com paraplegia, em virtude da compressão nervosa em nível de T10 com hipoestesia (diminuição da sensibilidade ao toque em determinada regiáo do corpo), ocorrendo também perda da força muscular e perda gradativa da sensibilidade.

Ainda internado, realizou o exame anatomopatológico para biópsia de tumor de mediastino posterior à esquerda com resultado microscópico de neoplasia maligna epitelial e diagnóstico de carcinoma embrionário 
pouco diferenciado com relato de imuno-histoquímica, apoiando o diagnóstico de carcinoma pouco diferenciado expressando difusamente CD30. Os exames laboratoriais do paciente (Tabela 1) apresentaram alteraçóes para desidrogenase lática (DHL), gonadotrofina coriônica humana (HCG), e negativo para alfafetoproteína (AFP).

Tabela 1. Exames laboratoriais do paciente com valores de referência para o sexo masculino

\begin{tabular}{|c|c|c|c|}
\hline Data & Exame & Resultado & $\begin{array}{l}\text { Valor de } \\
\text { referência }\end{array}$ \\
\hline \multirow{5}{*}{$17 / 4 / 18$} & Desidrogenase & \multirow{2}{*}{$2.238 \mathrm{U} / \mathrm{L}$} & \multirow{2}{*}{$135-225 \mathrm{U} / \mathrm{L}$} \\
\hline & láctica & & \\
\hline & Beta-HCG & & $<10$ \\
\hline & sérico & 1,5 & $\langle 1,0$ \\
\hline & Alfafetoproteína & $3,02 \mathrm{ng} / \mathrm{mL}$ & $<10,9 \mathrm{ng} / \mathrm{ml}$ \\
\hline \multirow{2}{*}{$07 / 5 / 18$} & Desidrogenase & \multirow{2}{*}{$2.373 \mathrm{U} / \mathrm{L}$} & \multirow{2}{*}{$135-225 \mathrm{U} / \mathrm{L}$} \\
\hline & láctica & & \\
\hline \multirow[t]{2}{*}{$14 / 5 / 18$} & Desidrogenase & \multirow[t]{2}{*}{$1.237 \mathrm{U} / \mathrm{L}$} & \multirow{2}{*}{$135-225 \mathrm{U} / \mathrm{L}$} \\
\hline & láctica & & \\
\hline
\end{tabular}

O paciente realizou uma nova tomografia computadorizada, ainda em abril, com achados de lesão expansiva com extensão ao longo da musculatura paravertebral de T3-T11 e invasão piramidal de T7-T8 associada a nódulos pulmonares (Figura 2).

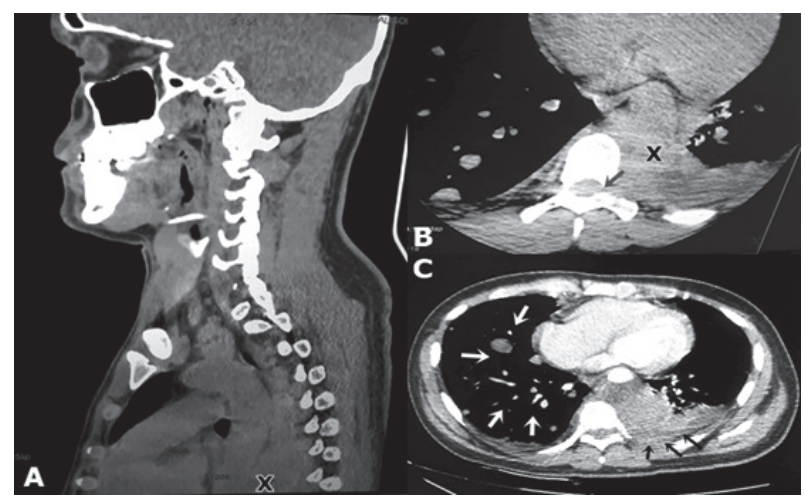

Figura 2. Tomografia computadorizada do paciente realizada no $\mathrm{HOL}$. A: plano sagital evidenciando a musculatura paravertebral e massa tumoral representada pelo $x$ preto; $B$ : invasão piramidal evidenciada pela seta preta e massa tumoral evidenciada pelo x preto; C: plano axial evidenciando nódulos metastáticos pulmonares (setas brancas) e derrame pleural (setas pretas)

Posteriormente ao resultado da biópsia, análise dos exames de imagem e quadro clínico do paciente, foi constatado que se tratava de um tumor mediastinal maligno com invasão de coluna, classificado como carcinoma de células embrionárias extragonodal de mediastino posterior. O paciente foi transferido para a Oncoclínica onde deu início ao tratamento quimioterápico, realizando um ciclo de bleomicina, etoposido e cisplatino (BEP) em maio de 2018 com duração de sete dias.
Após a quimioterapia, o paciente evoluiu clinicamente estável e sem intercorrências graves, cursando ainda com a paraplegia. Recebeu alta em maio de 2018 para acompanhamento e realização de quimioterapia ambulatorial. O câncer, no momento da alta, foi de estágio IV, por causa do quadro de metástase pulmonar.

O paciente realizou quimioterapia ambulatorial no HOL durante um período de oito meses, finalizando o tempo de acompanhamento em dezembro de 2018. Ao término das sessóes de quimioterapia, o paciente apresentou como resposta clínica a diminuição do tamanho da massa tumoral mediastinal, porém, seguiu apresentando paraplegia em membros inferiores. Após o final dos ciclos de quimioterapia, o paciente retornou para seu município de origem.

\section{DISCUSSÃO}

No caso em questão, além do tumor mediastinal, o paciente apresentou metástase pulmonar, achados estes encontrados nos exames de imagem que mostraram material tecidual com densidade de partes moles no mediastino posterior em situação vertebral à esquerda e discretamente à direita, lesão expansiva com extensão ao longo da musculatura paravertebral de T3-T11 e invasão intrapiramidal T7-T8 associada a nódulos pulmonares de distribuição randômica.

Para auxílio e complementação no diagnóstico de carcinoma embrionário do paciente, foi realizado o exame de imuno-histoquímica com resultado de carcinoma pouco diferenciado expressado difusamente CD30.

Após o diagnótico, o paciente realizou o primeiro ciclo de quimioterapia BEP. Ao término dos ciclos de quimioterapia, ainda internado, houve a diminuição do volume tumoral, porém, o mesmo seguiu com a paraplegia por conta da compressão nervosa.

Neste caso, o tumor seminomatoso produziu beta-HCG e HDL e não produziu AFP, sendo realizada a dosagem de beta-HCG e AFP apenas antes da realizaçáo da quimioterapia; já a dosagem de HDL antes da quimioterapia mostrou-se elevada e, após a quimioterapia, diminuiu, o que mostra a reduçáo do volume tumoral.

Em particular, sabe-se que os tumores de células germinativas não seminomatosas, nos quais as lesões primárias estão no mediastino, resultam em prognósticos vitais extremamente desfavoráveis. A taxa de sobrevida em cinco anos é de aproximadamente $40 \%$, embora isso varie entre os estudos ${ }^{8,9}$.

Não foi possível identificar fatores de risco ambientais, ocupacionais ou virais, porém há associaçôes causais com fatores genéticos, hormonais, congênitos (testículos não descidos) e adquiridos (atrofia e trauma testicular) ${ }^{10}$. 
Os vários achados radiológicos do paciente permitiram o diagnóstico e a conduta terapêutica a ser aplicada. Uma vez que estudos ${ }^{11,12}$ mostram que a imaginologia é fundamental para o estadiamento e decisáo terapêutica desses tumores, permite decidir a melhor via de abordagem cirúrgica e apreciar a extensão da doença e os sinais de invasão de estruturas adjacentes.

Os tumores de origem germinativa mostram habitualmente massas de grandes dimensóes, heterogêneas, com margens irregulares que sugerem malignidade, podendo igualmente evidenciar invasão das estruturas mediastinais, vias aéreas centrais, e pleura ${ }^{12}$.

Estudos $^{9,13}$ na literatura mostram que esses tumores frequentemente se infiltram nos órgãos adjacentes durante o progresso e, como resultado, são difíceis de retirar completamente cirurgicamente.

Os tumores germinativos não seminomatosos (85\%) e os seminomatosos (10\%) apresentam capacidade de sintetizar glicoproteínas que são utilizadas como marcadores tumorais (HCG e AFP e DHL). O HCG e AFP estáo relacionados com a atividade do tumor, e os níveis de LDH correlacionam-se com o volume tumoral ${ }^{10}$. As concentraçóes de AFP e beta-HCG elevadas ou em elevação significam doença em atividade com a necessidade de tratamento subsequente. Após quimioterapia ou cirurgia, as concentraçōes dos marcadores tumorais devem cair de acordo com suas meias-vidas: cinco a sete dias para AFP e 30 horas para a beta-HCG ${ }^{6}$.

A literatura traz os CD30, CD117, PLAP e OCT3/4 como marcadores de imunocoloraçáo altamente específicos para o carcinoma embrionário, sendo úteis para diagnósticos confirmativos em razão da sua sensibilidade e especificidade especialmente altas ${ }^{9,14}$.

Um estudo ${ }^{15}$ com 40 pacientes mostrou que a quimioterapia baseada em cisplatina é o tratamento padráo, levando à melhora da sobrevida em pacientes com tumor de células germinativas mediastinais. Mais de 90\% dos pacientes do estudo ${ }^{15}$ receberam quimioterapia como linha de frente tratamento, sendo o BEP o regime mais comumente utilizado (87\%).

Curiosamente, os cânceres testiculares estão entre os cânceres mais responsivos à quimioterapia. Com a quimioterapia convencional e a cirurgia, $99 \%$ dos pacientes com doença em estágio inicial e $74 \%$ dos pacientes com doença em estágio avançado agora vivem pelo menos cinco anos ${ }^{16}$.

É importante ressaltar que o prognóstico do paciente em questão está ligado a dois fatores importantes que determinam o prognóstico vital no tratamento dos tumores de células germinativas do mediastino, sendo estes a metástase para os órgãos circundantes e sua resposta à quimioterapia ${ }^{9,17}$.
Como limitaçóes deste trabalho, pode-se citar o fato de, até o presente momento, haver incipiência de artigos e pesquisas científicas acerca do tema em questão que abordem especificamente os tumores mediastinais de origem germinativa com localizaçáo posterior. Esses aspectos poderão ser tratados em estudos futuros.

\section{CONCLUSÃO}

Este estudo relata o caso de um paciente jovem, com tumor raro de células germinativas e metástase pulmonar, que evoluiu clinicamente estável, apesar de continuar paraplégico, após tratamento específico com quimioterápicos.

Contudo, por tratar-se de uma doença rara e de maior incidência em jovens, ainda há uma escassa literatura com relação ao carcinoma de células embrionárias de mediastino.

A importância deste caso traz novas evidências e achados acerca do tema tratado, além de expandir o raciocínio diagnóstico para os tumores de mediastino, visto que é um raro diagnóstico diferencial a ser considerado e que, se constatado precocemente, favorece para um melhor prognóstico, sobretudo em pacientes jovens.

\section{CONTRIBUIÇÕES}

Flávia Adrianne de Castro Grello e Adrielly Elane de Sousa Maia realizaram a pesquisa de campo, análise de dados, revisão e elaboração e versão final do manuscrito. Katiane da Costa Cunha coordenou o estudo, participou do processo de revisão, correção e formatação para a versão final da submissão deste artigo. Todos os autores leram e aprovaram o manuscrito final.

\section{DECLARAÇÃO DE CONFLITO DE INTERESSES}

Nada a declarar.

\section{FONTES DE FINANCIAMENTO}

Não há.

\section{REFERÊNCIAS}

1. Kubota K, Yamada S, Kondo T, et al. PET imaging of primary mediastinal tumours. Br J Cancer. 1996;73(7):882-6. doi: https://doi.org/10.1038/ bjc. 1996.157

2. Malagón HD, Montiel DP. Mediastinal germ cell tumours. Diagnostic Histopathology. 2010;16(5):22836. doi: https://doi.org/10.1016/j.mpdhp.2010.03.002

3. Oosterhuis JW, Stoop H, Honecker F, et al. Why human extragonadal germ cell tumours occur in the midline of 
the body: old concepts, new perspectives. Int J Androl. 2007;30(4):256-63. doi: https://doi.org/10.1111/ j.1365-2605.2007.00793.x

4. Takeda S, Miyoshi S, Ohta M, et al. Primary germ cell tumors in the mediastinum: a 50-year experience at a single Japanese institution. Cancer. 2003;97(2):367-76. doi: https://doi.org/10.1002/cncr.11068

5. Macchiarini P, Ostertag H. Uncommon primary mediastinal tumours. Lancet Oncol. 2004;5(2):107-18. doi: https://doi.org/10.1016/S1470-2045(04)01385-3

6. Couto WJ, Gross JL, Deheinzelin D, et al. Tumores de células germinativas primários do mediastino. Rev Assoc Med Bras. 2006;52(3):182-6. doi: http://dx.doi. org/10.1590/S0104-42302006000300020

7. Nogueira AA, Guedes VR. Tumores de células germinativas não-seminomatosos: revisão da literatura. Rev Pat Tocantins. 2016;3(3):53-67.

8. Kesler KA, Rieger KM, Hammoud ZT, et al. A 25-year single institution experience with surgery for primary mediastinal nonseminomatous germ cell tumors. Ann Thorac Surg. 2008;85(2):371-8. doi: https://doi. org/10.1016/j.athoracsur.2007.09.020

9. Kawanami K, Wakao N, Kamiya M, et al. A case of mediastinal embryonal carcinoma successfully treated by integrative therapy. Nagoya J Med Sci. 2014;76(12):225-33.

10. Dias Neto JA, Domingos ALA, Martins ACP, et al. Prognóstico de tumores testiculares germinativos. Acta Cir. Bras. 2002;17(Suppl 3):55-8. doi: http://dx.doi. org/10.1590/S0102-86502002000900012

11. Godinho MTM. Tumores invasivos do mediastino anterior: abordagem diagnóstica e orientação terapêutica. Rev Port Pneumol. 1999;5(3):267-311. doi: https://doi. org/10.1016/S0873-2159(15)30990-9

12. Lucas MH, Rodrigues MF, Domínguez L, et al. Tumores de células germinativas primários do mediastino: a propósito de om caso clínico.Rev Port Pneumol 2001;7(2):145-51. doi: https://doi.org/10.1016/S08732159(15)30831-X

13. Kang CH, Kim YT, Jheon SH, et al. Surgical treatment of malignant mediastinal nonseminomatous germ cell tumor. Ann Thorac Surg. 2008;85(2):379-84. doi: https://doi.org/10.1016/j.athoracsur.2007.09.011

14. Iczkowski KA, Butler SL, Shanks JH, et al. Trials of new germ cell immunohistochemical stains in 93 extragonadal and metastatic germ cell tumors. Hum Pathol. 2008;39(2):275-81. doi: https://doi. org/10.1016/j.humpath.2007.07.002

15. Dechaphunkul A, Sakdejayont S, Sathitruangsak C, et al. Clinical characteristics and treatment outcomes of patients with primary mediastinal germ cell tumors: 10-Years' experience at a single institution with a bleomycincontaining regimen. Oncol Res Treat. 2016;39(11):68894. doi: https://doi.org/10.1159/000452259
16. Howlader N, Noone AM, Krapcho M, et al., editors. SEER Cancer Statistics Review (CSR) 1975-2013. Bethesda (MD): National Cancer Institute (US); 2016 Apr.

17. Liu TZ, Zhang DS, Liang Y, et al. Treatment strategies and prognostic factors of patients with primary germ cell tumors in the mediastinum. J Cancer Res Clin Oncol. 2011;137(11):1607-12. 